\title{
O PROGRAMA BOLSA FAMÍLIA NAS MICRORREGIÕES DO TOCANTINS: UMA ANÁLISE EXPLORATÓRIA
}

Bolsa Família Program in the micro-regions of Tocantins: an exploratory analysis

El Programa Bolsa Família en las microrregiones de Tocantins: un análisis exploratorio

\section{Juliana Aguiar de Melo¹, Mariana Acácio², Cleiton Silva Ferreira Milagres ${ }^{3}$}

${ }^{1}$ Professora do Curso de Economia-UFT, Doutoranda em Planejamento Urbano e Regional, UFRJ, Rio de Janeiro, Brasil.

${ }^{2}$ Graduanda em Ciências Econômicas, Universidade Federal do Tocantins, Palmas, Brasil

${ }^{3}$ Professor do Curso de Tecnologia em Gestão de Cooperativas-UFT, doutor em Desenvolvimento Regional-UFT, Palmas, Brasil.

\section{Artigo recebido em 15/05/2020 aprovado em 15/09/2020 publicado em 05/03/2021.}

\section{RESUMO}

O objetivo desse artigo é apresentar uma análise exploratória dos dados do Programa Bolsa Família no Tocantins, desagregados a nível de microrregiões, tendo como referencial teórico as teorias de Desenvolvimento Regional e a Abordagem da Capacitação Amartya Sen. Os principais indicadores utilizados foram valor dos repasses e a quantidade de famílias beneficiadas pelo Programa, coletados do Ministério da Cidadania. Ademais, o processamento estatístico contou também com indicadores socioeconômicos do Instituto Brasileiro de Geografia e Estatística. Os resultados indicam haver uma fase de expansão e outra de contração da presença do programa no estado. Além disso, Jalapão e Bico do Papagaio destacam-se como as microrregiões com maior volume de repasses e beneficiários por habitante no Tocantins. Por fim, foi observado que a distribuição do programa nas microrregiões tocantinenses não se apresentou de forma homogênea, nem no tempo e nem no espaço, levando em consideração os anos analisados.

Palavras-chave: Programa Bolsa Família, Desenvolvimento Regional, Transferência Condicionada de Renda.

\section{ABSTRACT}

The objective of this article was to present an exploratory analysis of the data from the Bolsa Familia Program in Tocantins, disaggregated at the level of microregions, with the theoretical framework of Regional Development theories and Capability Approach. The main indicators used were the value of transfers and the number of families benefited by the Program, collected from the Ministry of Citizenship. In addition, the statistical processing also included socioeconomic indicators from Brazilian Institute of Geography and Statistics. The results indicate that there is a period of expansion and another of contraction of the program in the state. In addition, Jalapão and Bico do Papagaio stand out as the micro-regions with the highest volume of transfers and beneficiaries per inhabitant in Tocantins. Finally, it was observed that the distribution of the program in the Tocantins' microregions was not homogeneous, neither in time nor in space, considering the years analyzed.

Keywords: Bolsa Família Program, Regional Development, Conditional Cash Transfer.

\section{INTRODUÇÃO}

Com pouco mais de três décadas de criação, o estado do Tocantins possui IDH de 0,699 , considerado médio, ocupando a décima quarta posição no ranking nacional. Segundo o Radar do IDHM ${ }^{1}$ (IPEA, 2019) que monitora as tendências do índice e de seus

\footnotetext{
${ }^{1}$ Com base nas informações produzidas pela Pesquisa Nacional por Amostra de Domicílio (PNAD) Contínua, do Instituto Brasileiro de Geografia e Estatística (IBGE) entre 2012 e 2017.
} 
componentes nos anos intercensitários, o IDHM agregado a nível estadual do Tocantins em 2017 é 0,743 - considerado alto $^{2}$. Contudo, a decomposição do IDHM mostra que a melhora desse indicador se deve às dimensões de educação e longevidade, visto que a dimensão renda teve leve piora decorrente de quedas na renda per capita (IPEA, 2019). Neste sentido, é possível que a melhoria nestes indicadores esteja associada a políticas públicas de universalização da educação básica e ao Sistema Único de Saúde.

Em 2010, a esperança de vida ao nascer no estado era de 73 anos e, 20 a cada mil crianças nascidas não sobreviviam ao primeiro ano de vida. Com $45 \%$ da população vulnerável à pobreza, $18 \%$ das famílias do Tocantins tinham como chefe de família mães sem ensino fundamental completo (PNUD, 2013).

Nesse contexto de vulnerabilidade social, o Programa Bolsa Família se consolidou como principal mecanismo de distribuição de renda em todo o Brasil. O programa consiste em um mecanismo de transferência condicionada de renda direcionado às famílias em situação de pobreza e de extrema pobreza. Graças à grande cobertura e à boa focalização nos mais pobres, o PBF tem contribuído para a redução da pobreza, em particular da pobreza extrema. Além disso, essas transferências também foram um fator importante para a queda da desigualdade (IPEA, 2019).

O aporte teórico desta pesquisa centrará nas teorias de desenvolvimento regional, pois compreende uma análise de fatores sociais e econômicos no interior de uma região - quando bem empregados em uma determinada região - podem reduzir as desigualdades regionais e fomentar o desenvolvimento socioeconômico (Oliveira et al., 2019). Dessa forma, uma pesquisa exploratória que busque compreender como o principal mecanismo de transferência direta de renda nacional se distribui espacialmente pode ter grande utilidade para direcionar futuras políticas públicas baseadas em evidência, bem como o processo de tomada de decisões a nível regional, influenciando diretamente no desenvolvimento socioeconômico do Tocantins.

Portanto, o objetivo deste trabalho consiste em apresentar uma análise exploratória da distribuição das transferências de renda do Programa Bolsa Família entre as microrregiões do estado do Tocantins. Para tanto, foram selecionadas cinco variáveis, que representam os valores dos repasses e o volume da população atendida por microrregião, resultando em uma análise mais ampla dos dados, além de tecer associações dos resultados encontrados às dinâmicas socioeconômicas regionais.

\section{Divisão regional do Tocantins}

Criado pela Constituição Federal de 1988, o Estado do Tocantins ocupa uma área de 7,0\% da região Norte do Brasil, e 3,3\% do território nacional. Limitase ao norte com os Estados do Maranhão e do Pará; ao sul com o Estado de Goiás; ao leste com os Estados do Maranhão, do Piauí e da Bahia; e ao oeste com os Estados do Pará e do Mato Grosso.

Possui uma área de 277.620,9 km² e, em 2019, uma população de 1,6 milhões de pessoas, segundo projeção do IBGE. A taxa de urbanização do estado é de 79\%, apenas cinco pontos percentuais abaixo da taxa de urbanização nacional (84\%). A densidade demográfica, por sua vez, é bem abaixo do índice

\footnotetext{
${ }^{2}$ De acordo com a classificação do Programa das Nações Unidas para o Desenvolvimento, índices entre 0,700 e 0,799 são considerados altos.
} 
nacional: 4,3 habitantes por $\mathrm{km}^{2}$ no Tocantins contra 23,8 habitantes por $\mathrm{km}^{2}$ no Brasil (IBGE, 2010).

O estado possui 139 municípios, distribuídos entre três regiões geográficas intermediárias: Araguaína, Gurupi e Palmas; e onze regiões geográficas imediatas: Araguaína, Araguatins, Colinas do Tocantins, Dianópolis, Guaraí, Gurupi, Miracema do Tocantins, Palmas, Paraíso do Tocantins, Porto Nacional e Tocantinópolis (IBGE, 2017).

Entre 1989 e 2017, o sistema de divisão regional brasileira do IBGE se dividia em mesorregiões e microrregiões. A Divisão Regional do Brasil de 1989, ocorreu no contexto de reforço ao movimento de descentralização do poder, no qual a Constituição de 1988, consagrava um pacto federativo que aprofunda a competência de estados e municípios sobre seus respectivos territórios (IBGE, 2017). Essa divisão segue relevante, uma vez que é o recorte adotado por uma extensa bibliografia, bem como por diversas bases de dados do IBGE.

$\mathrm{Na}$ Figura 1 são apresentadas as oito microrregiões - Araguaína, Bico do Papagaio, Dianópolis, Gurupi, Jalapão, Miracema do Tocantins, Porto Nacional e Rio Formoso - entre as quais se distribuem os municípios do Tocantins.

Recentemente, estudos como o de Oliveira e Rodrigues (2019) demonstraram que todas as microrregiões do Tocantins possuem atividades produtivas em destaque, bem como núcleos urbanos que polarizaram uma parte do estado. Nesse cenário, a agropecuária, a administração pública, o comércio e demais serviços em geral — são a base das suas economias. As atividades industriais, por outro lado, não possuem protagonismo na pauta estadual.

Em 2017, o Tocantins possuía apenas cinco municípios de grande porte: Palmas, Araguaína, Gurupi, Porto Nacional e Paraíso do Tocantins, respectivamente. Dois deles estão localizados na microrregião de Porto Nacional (Palmas e Porto Nacional), Araguaína e Gurupi estão localizados em suas microrregiões homônimas, e Paraíso do Tocantins pertence a microrregião de Rio Formoso. Como vem se debatendo sobre o urbano e rural no Brasil, os critérios que são adotados para a definição de urbano ressaltam as funções administrativas que são atribuídas aos aglomerados, sem levar em conta se estes possuem capacidade para assumir a posição de centralidade (Wanderley, 2009).

Figura 1. Microrregiões do Tocantins.

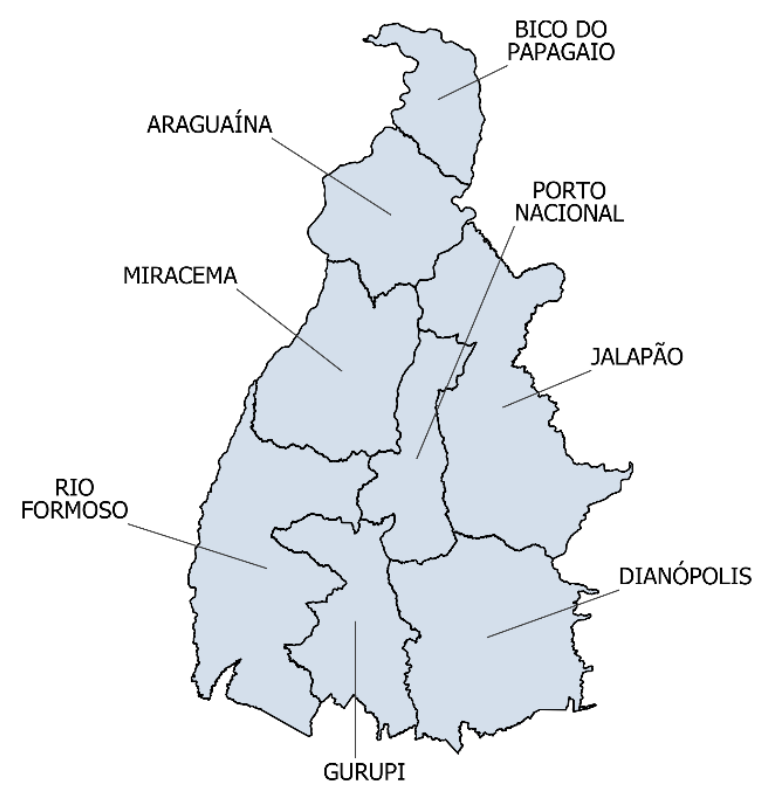

Fonte: Elaborado pelos autores.

Ainda segundo Wanderley (2009), a maioria das cidades que possuem população inferior a $50 \mathrm{mil}$ habitantes não oferecem condições mínimas para assumir a vocação de centralidade, sendo atribuída somente como reconhecimento legal, enquanto espaços urbanos. Nesse sentido, essas cinco cidades - Palmas, Araguaína, Gurupi, Porto nacional e Paraíso do Tocantins - possuem caraterísticas de centralidade, 
concentrando serviços essenciais e dinamismo do ponto de vista econômico, enquanto boa parte dos demais municípios possuem características de marginalidade, com pouca infraestrutura urbana e sem uma dinâmica econômica local.

A capital do estado, Palmas, está localizada na microrregião de Porto Nacional. Ela é a última cidade planejada do século XX e a capital mais nova do país. Criada nos moldes de Brasília, apresenta áreas de preservação ambiental, praças, hospitais, escolas (Oliveira, 2009). Como esperado, possui a dinâmica econômica mais complexa do Estado, sendo responsável por quase $25 \%$ do Produto Interno Bruto do Tocantins em 2017 (IBGE). Segundo o IBGE, foi a capital com maior crescimento populacional entre 2016 e 2017, ganhando 17 mil novos habitantes no período.

Gráfico 1. PIB per capita e percentual de pessoas em situação de pobreza nas Microrregiões do Tocantins 2010

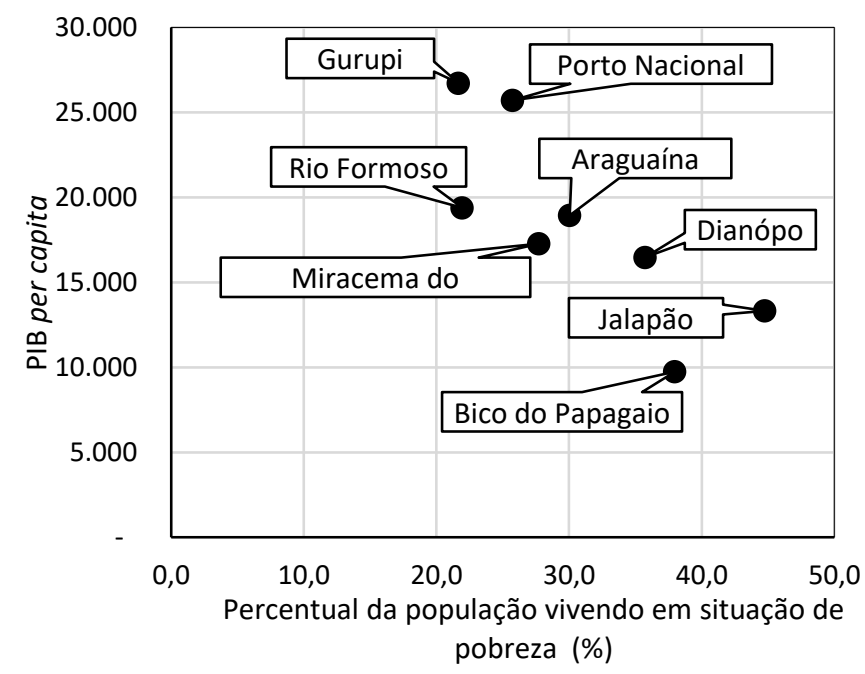

Fonte: Elaboração própria, a partir dos dados do IBGE (2010).

\footnotetext{
${ }^{3}$ Média do percentual da população vivendo em situação de
} pobreza dos municípios pertencentes a determinada região.
O Gráfico 1 apresenta um diagrama de dispersão entre o PIB per capita e o percentual de pobres $^{3}$ por microrregião para o ano de 2010.

Conforme demostrado no diagrama, as microrregiões de Gurupi e Porto Nacional combinam um alto PIB per capita e um baixo percentual de pobres em relação ao restante do Tocantins. As microrregiões de Rio Formoso, Araguaína, Miracema do Tocantins e Dianópolis encontram-se em uma situação média, segundo esses dois indicadores.

Por outro lado, Jalapão e Bico do Papagaio são as microrregiões mais vulneráveis em termos socioeconômicos: conjugam um baixo PIB per capita e um alto percentual de pobres. Segundo Oliveira e Strassburg (2014), trata-se de regiões de extrema pobreza, com grandes desigualdades sociais e econômicas.

A região do Jalapão foi por muito tempo reconhecida como território isolado, desprovido de infraestrutura e com uma alta vulnerabilidade social. A dinâmica das novas cidades criadas às margens da rodovia BR -153 no Tocantins ocasionou no processo de saída de parte da população regional para os novos centros urbanos criados, confirmando os argumentos de Wanderley (2009) acerca da centralidade.

O estudo de Milagres (2020) sobre os dilemas do desenvolvimento regional no Jalapão postula que a questão do acesso é uma das principais vulnerabilidades que afeta e desencadeia em inúmeros problemas na dinâmica socioeconômica local. A dificuldade da população para se deslocar entre os municípios da região ou mesmo para os centros urbanos mais próximos é um problema que afeta diretamente a busca por melhorias nas estruturas coletivas tais como: acesso à saúde, saneamento 
básico, educação, emprego, segurança pública entre outras. Para o autor, ainda que o Jalapão tenha obtido visibilidade e notoriedade na última década por conta da exploração turística, existe um problema crucial que é a grande desigualdade social e a pobreza.

Quanto a região do Bico do Papagaio, a pesquisa desenvolvida por Beraldo (2016) atribui a luta pela terra como um dos problemas que marcaram a região. Não diferente do que ocorre na região do Jalapão, o Bico do Papagaio possui dificuldades quanto ao acesso ao ensino superior, falta de escolas, hospitais e estradas que evidenciam a falta de oportunidades e diminui as chances de redução da pobreza. Ainda que duas grandes rodovias federais (Belém-Brasília e Transamazônica) possam reduzir as dificuldades, para a autora, a população rural tem que lidar com problemas para escoar a produção, para terem acesso à escola, saúde, entre outros serviços, devido à ausência ou condições precárias das estradas vicinais nas comunidades rurais, principalmente nos assentamentos rurais.

\section{Programa Bolsa Família no Tocantins}

O Programa Bolsa Família - PBF foi criado no ano de 2003, objetivando unificar todos os programas assistenciais que tinham como base a transferência de recursos monetários para combate à pobreza. Sendo o principal mecanismo de transferência direta de renda nacional, é direcionado às famílias em situação de pobreza e de extrema pobreza, de modo que consigam superar a situação de vulnerabilidade e pobreza. Em 2013, beneficiou cerca de 13,8 milhões de famílias, equivalente a um quarto da população brasileira (IPEA, 2019).

No Tocantins, entre 2007 e 2017, os repasses do Programa Bolsa Família para o estado somaram quase 3 bilhões de reais. Em 2013 quando atingiu o ápice de participantes no estado - beneficiou mais de 140 mil famílias. Nesse ano, cada família participante do Programa recebia, em média, $R$ \$ 199,00 por mês.

A população-alvo do programa é constituída por famílias em situação de pobreza ou extrema pobreza. São consideradas famílias extremamente pobres aquelas que têm renda mensal de até $\mathrm{R} \$ 89,00$ por pessoa, e famílias pobres aquelas que têm renda mensal entre $R \$$ 89,01 e R \$ 178,00 por pessoa. A participação das famílias pobres no programa está condicionada à existência de gestantes e crianças ou adolescentes (entre 0 e 17 anos) em sua composição. O PBF é a política de transferência de renda mais progressiva feita pelo governo federal. Cerca de $70 \%$ dos seus recursos alcançam os $20 \%$ mais pobres (IPEA, 2019).

Ainda segundo estudo do IPEA (2019) - feito a partir da análise das PNADs de 2001 a 2015 e das PNADs Contínuas de 2016 e 2017 - o programa é, por larga margem, o benefício monetário mais bem focalizado no Brasil. Por conseguir conjugar focalização com uma enorme cobertura, o programa se tornou uma peça fundamental no sistema de proteção social brasileiro.

\section{Referencial Teórico}

Desenvolvimento Regional

Apesar de ser uma preocupação presente em toda a história das Ciências Econômicas, somente após a Segunda Guerra Mundial, o desenvolvimento econômico se tornou um forte campo de estudo específico - apesar da obra de Schumpeter em 1911. Crescimento e desenvolvimento econômico deixaram 
de ser considerados sinônimos e suscitaram diversos debates a respeito de suas abordagens.

Para Schumpeter (1911), desenvolvimento econômico corresponderia ao rompimento do fluxo circular através das inovações, enquanto crescimento econômico seria a intensificação do fluxo circular sem a ocorrência de inovações. Lucas (1988), por sua vez, recomenda que a definição de desenvolvimento econômico seja limitada ao crescimento da renda per capita.

Autores como Raj (1998), por outro lado, argumentam em favor da multidimensionalidade do conceito de desenvolvimento, que deve incluir melhoras nos indicadores sociais. Sachs (2004) compreende o desenvolvimento em termos de universalização e do exercício efetivo de todos os direitos humanos: políticos, civis e cívicos; econômicos, sociais e culturais; além de direitos coletivos ao desenvolvimento e ao ambiente.

Também no período após a Segunda Guerra Mundial — na década de 1950 — , surge um campo da ciência dedicado ao estudo do desenvolvimento regional. Ou seja, ao estudo da dinâmica do processo de desenvolvimento econômico aplicado às regiões arbitrariamente delimitadas, tendo como elemento indispensável a localização espacial dessas áreas. Segundo Aydalot (1985) a Economia Regional preocupa-se com as razões da distribuição heterogênea das atividades produtivas no âmbito de um determinado espaço geográfico e com os processos que levam ao declínio e ao progresso socioeconômico dessas regiões. A maior parte das teorias que visam ao crescimento e desenvolvimento de regiões específicas apresenta o Estado como agente ativo nesse processo.

Para Myrdal (1957), além de existirem disparidades entre países existe também disparidades dentro dos próprios países — tendo em vista que existem regiões desenvolvidas em países nãodesenvolvidos e vice-versa. $\mathrm{O}$ autor argumenta ainda que concentração em uma determinada localidade não controlada pela política intervencionista pode resultar em estagnação em outras localidades, sendo a solução mudanças contrárias ao efeito cumulativo para enfraquecer o processo de causação circular cumulativa, a partir de um plano de desenvolvimento e integração nacional, buscando intervir de forma estratégica nas forças de mercado.

Segundo François Perroux (1967) o crescimento não surge em todo lugar ao mesmo tempo, manifesta-se em pontos ou polos de crescimento, com intensidades variáveis e é transmitido através de diversos canais e com efeitos finais nas variáveis que compõe a economia. E, ainda, somente através de uma organização consciente e deliberada, por parte do Estado, do meio de propagação dos efeitos do polo de desenvolvimento seria possível alcançar o crescimento, e o desenvolvimento, de um conjunto de territórios e suas respectivas populações.

Elementos que podem ser fundamentais para o desenvolvimento e melhoria da qualidade de vida em determinada localidade ou região podem não ser para outras, demonstrando a necessidade de um estudo de caso a caso (Oliveira e Piffer, 2018).

\section{A abordagem da Capacitação}

Amartya Sen (2000) propôs uma estrutura de pensamento alternativa para analisar a pobreza, como alternativa ao uso exclusivo da renda per capita como determinante do bem-estar dos indivíduos - e tampouco utilizar medições psicológicas como felicidade. A abordagem da capacitação vai além dos bens e serviços que as pessoas podem consumir: ela 
se preocupa com o que as pessoas são capazes de fazer com esses bens e serviços. Sen (2000) chama de capacidades as diferentes combinações de funcionamentos que uma pessoa pode atingir com um bem. Na perspectiva do autor, crescimento econômico - usualmente aferidos por indicadores como o Produto Interno Bruto e índices de consumo e industrialização - é importante enquanto um meio, e não um fim, para se atingir o desenvolvimento.

$\mathrm{Na}$ abordagem da capacitação, Sen (2000) distingue especialmente dois tipos de liberdades: instrumentais e constitutivas. A liberdade instrumental diz respeito à capacidade das pessoas de ter uma vida como elas desejarem — não sendo imposto um estilo de vida, como ocorre em governos autoritários. Sendo assim, a melhor forma de governo para garantir essa liberdade é a democracia. Por liberdade constitutiva entende-se como o direito a participação política, educação básica e assistência médica, vida em comunidade, além do próprio exercício da cidadania sem repressões, como a liberdade de expressão.

O grau de capacitação das pessoas é influenciado por oportunidades econômicas, liberdades políticas, poderes sociais e por condições habilitadoras, como boa saúde e educação básica (Sen, 2000). Dessa forma, as liberdades instrumentais não apenas contribuem para o desenvolvimento, mas também são cruciais para o fortalecimento e expansão das próprias liberdades constitutivas - funcionando como uma via de mão dupla. De modo inverso, privações de algum tipo de liberdade contribuem para privações de outros tipos de liberdade (Oliveira, 2009).
Nessa abordagem, a pobreza vista deve ser entendida como privação de capacitações básicas, representando a ausência de algumas capacitações básicas para funcionar, ou seja, a carência pessoal de oportunidades para realizar alguns níveis minimamente aceitáveis de funcionamentos. Os funcionamentos vão desde estar bem nutrido e estar adequadamente vestido até às realizações sociais mais complexas, como participar da vida em comunidade.

As duas perspectivas da pobreza, renda e capacitações, estão fortemente associadas. Um aumento de capacitação pode levar a um aumento de renda, contribuindo para a redução da pobreza por renda, e vice-versa.

A abordagem das capacidades de Amartya Sen é a base teórica por trás do consagrado Índice do Desenvolvimento (IDH) - cujo $\mathrm{PNUD}^{4}$ é o responsável pela elaboração e publicação. O índice apresenta três dimensões - Renda, Educação e Longevidade, e busca ser um contraponto ao PIB per capita, outro indicador muito utilizado como proxy de desenvolvimento. Apesar de não abranger todos os aspectos do desenvolvimento humano, o IDH tem o mérito de sintetizar a compreensão do tema e fomentar o debate acerca da complexidade do desenvolvimento humano, que vai muito além da renda (PNUD, 2013).

\section{MATERIAIS E MÉTODOS}

Os dados relativos ao Programa Bolsa Família correspondem às informações fornecidas pelo Ministério da Cidadania e disponibilizados pelo portal Vis Data. A espacialidade adotada foi a de microrregiões do estado do Tocantins e a temporalidade dos dados encontra-se entre 2007 e

\footnotetext{
${ }^{4}$ Programa das Nações Unidas para o Desenvolvimento
} 
2017. As variáveis de interesse disponibilizadas pelos dados secundários do governo foram: número de famílias beneficiadas, valor total repassado e valor médio repassado. A combinação entre esses indicadores e dados demográficos do IBGE nos permitiu elaborar duas outras variáveis de interesse: proporção de beneficiários na população e o valor per capita dos repasses.

Para o denominador de população utilizou-se a população total. Para 2007 foram utilizados dados da Contagem da População, e para 2010, dados do Censo Demográfico. Os demais dados provêm da série de população estimada 2001 a 2006, 2008 a 2009 e 2011 a 2019.

Os dados que, geralmente, foram disponibilizados com o recorte municipal foram agregados em microrregiões. Além disso, os valores disponibilizados a preços correntes foram convertidos em preços constantes de 2017. Para isso, foi utilizado o Índice Nacional de Preços ao Consumidor - INPC, de dezembro de cada ano. Nesta primeira etapa, os dados foram manipulados em planilhas de Excel.

Ademais, foi elaborado um banco de indicadores socioeconômicos para os municípios do Tocantins, a partir de dados do IBGE. As variáveis de interesse foram: PIB por município — também deflacionados pelo INPC a valores constantes de dezembro de 2007, Índice de Gini, Taxa de Desocupação - para 18 anos ou mais, Expectativas de Anos de Estudo, Mortalidade infantil, Índice de atendimento total de água e Índice de atendimento total de esgoto.

Os passos seguintes da pesquisa consistiram na aplicação técnicas de análise exploratória de dados espaciais (AEDE) objetivando: a. Visualizar e descrever distribuições espaciais, identificar padrões de associação espacial: aglomerados espaciais ou clusters;

b. Identificar observações atípicas: valores extremos ou outliers.

Nesta etapa, foram geradas estatísticas descritivas com o auxílio dos softwares Excel e GeoDa.

\section{RESULTADOS E DISCUSSÃO}

Tocantins

Entre 2007 e 2017, os repasses do Programa Bolsa Família para o estado do Tocantins cresceram $73,5 \%$ - as cifras foram de 156 milhões para 270 milhões de reais (Gráfico 2). O número de famílias atendidas (Gráfico 5) cresceu 20\% no período - eram 107 mil em 2007, e 125 mil em 2017.

O valor médio (Gráfico 3) dos repasses cresceu $48 \%$ no período, próximo à variação dos valores repassados per capita dos repasses (Gráfico 5), que foi de $40 \%$ no período. Em 2007, cada família participante do Programa recebia, em média, R\$ 121,00 por mês. Em 2017, esse valor era de R\$179,00.

Gráfico 2. Valor total dos repasses no Tocantins - Em mil reais por ano.

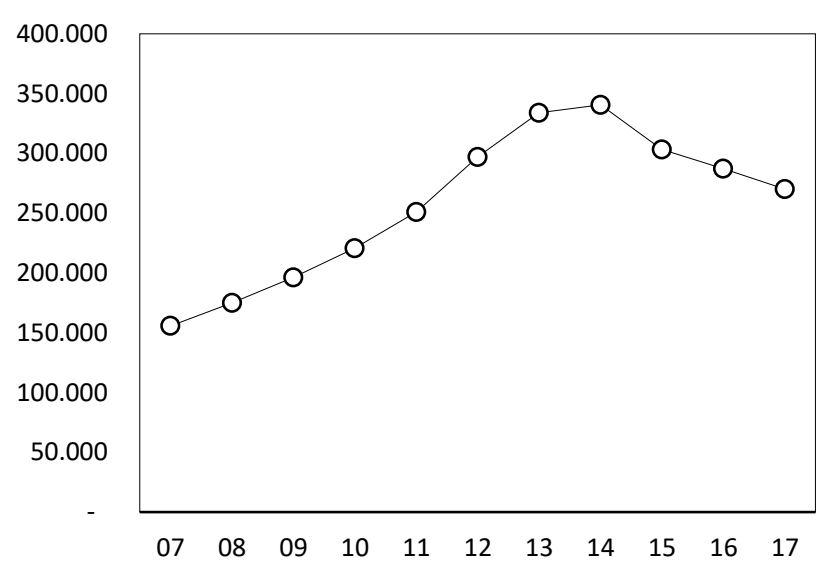

Fonte: Elaboração própria, a partir dos dados do Ministério da Cidadania (2007 a 2017) e IBGE (2019). 
Gráfico 3. Valor médio dos repasses no Tocantins - Em reais por ano.

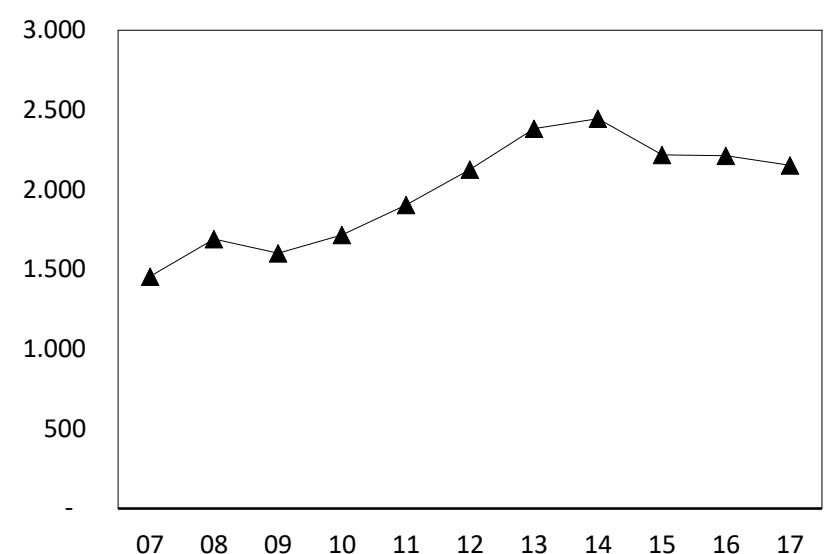

Fonte: Elaboração própria, a partir dos dados do Ministério da Cidadania (2007 a 2017) e IBGE (2019).

Gráfico 4. Valor per capita dos repasses no Tocantins - Em reais por ano.

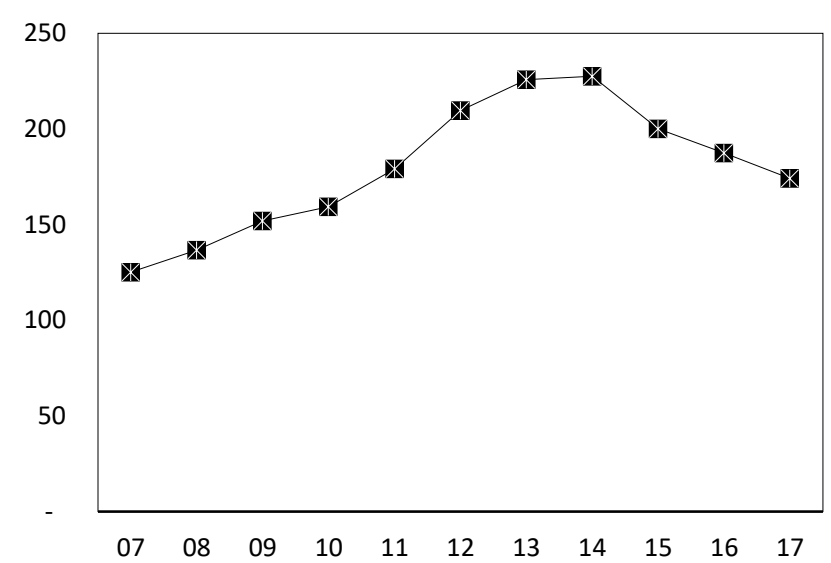

Fonte: Elaboração própria, a partir dos dados do Ministério da Cidadania (2007 a 2017) e IBGE (2019).

A proporção de beneficiários (Gráfico 6) na população é a exceção: apresentou variação líquida negativa na comparação entre 2007 e 2017 (6\%). A quantidade de pessoas que pertencem às famílias participantes do programa em relação a população total do Tocantins cresceu mais de $17 \%$ entre 2008 e 2009 saltou de $8,1 \%$ da população para 9,5\%. Entre 20102015 a proporção de beneficiários no Tocantins oscilou entre $9 \%$ e $9,9 \%$. Apresentou queda acumulada de
10,5\% nos últimos anos de análise, retornando ao patamar de 2007.

Gráfico 5. Quantidade de famílias beneficiadas no Tocantins - Por ano.

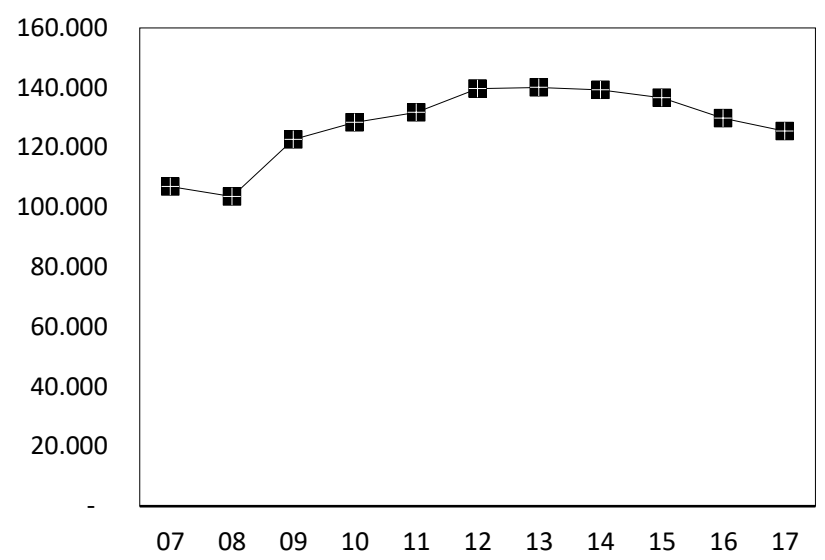

Fonte: Elaboração própria, a partir dos dados do Ministério da Cidadania (2007 a 2017) e IBGE (2019).

Gráfico 6. Proporção de beneficiários na população do 114 Tocantins - Em porcentagem por ano.

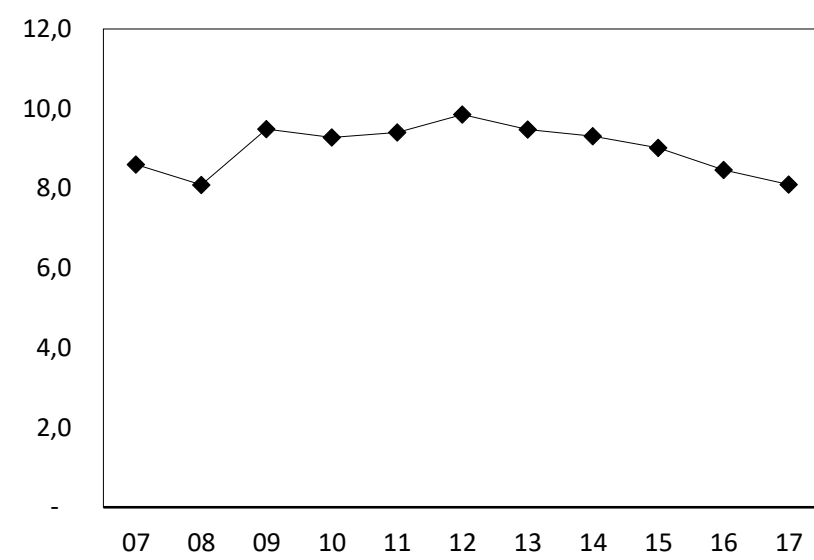

Fonte: Elaboração própria, a partir dos dados do Ministério da Cidadania (2007 a 2017) e IBGE (2019).

Os percentuais de evolução ano a ano para os indicadores do PBF no Tocantins - valor total dos repasses, valor médio dos repasses, valor per capita dos repasses, quantidade de famílias beneficiadas e proporção de beneficiários na população - podem ser observadas nos Gráficos 7 e 8. 
Gráfico 7. Variação em relação ao ano imediatamente anterior - Em porcentagem (\%).

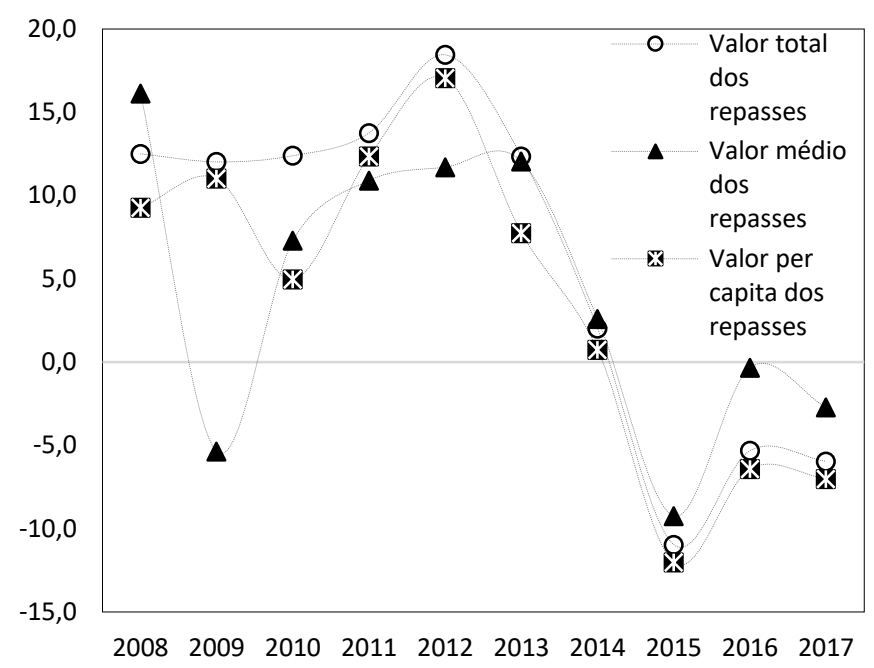

Fonte: Elaboração própria, a partir dos dados do Ministério da Cidadania (2007 a 2017) e IBGE (2019).

Gráfico 8. Variação em relação ao ano imediatamente anterior - Em porcentagem (\%).

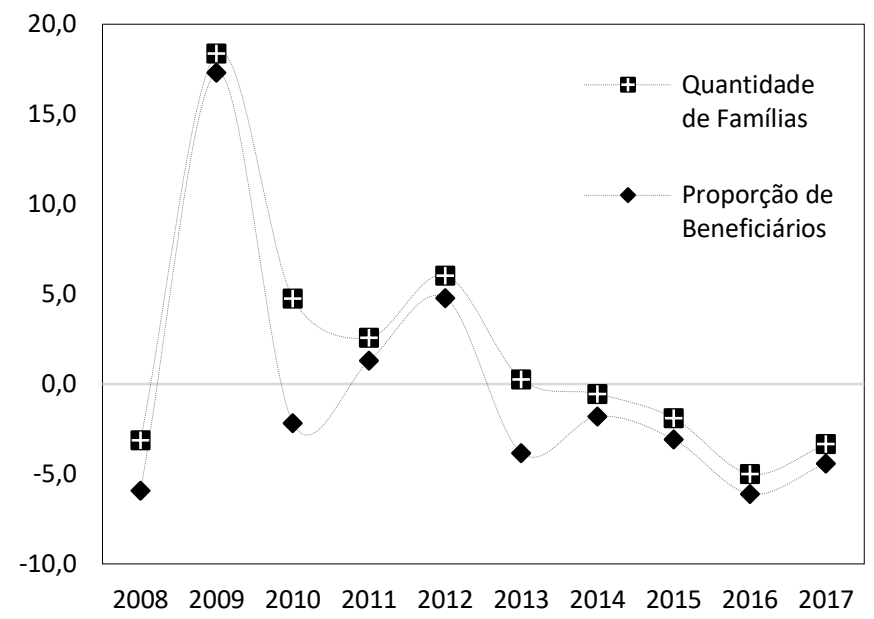

Fonte: Elaboração própria, a partir dos dados do Ministério da Cidadania (2007 a 2017) e IBGE (2019).

\section{Microrregiões}

O Bico do Papagaio foi a microrregião que mais recebeu recursos do governo federal relacionados ao Programa Bolsa Família (Gráfico 9). Foram mais de
600 milhões de reais em transferências de renda no período analisado. Em 2017, cerca de 25.000 mil famílias recebiam, em média, R\$190,00 por mês na microrregião. $\mathrm{O}$ valor médio repassado é $42 \%$ maior que em 2007, e o número de famílias atendidas cresceu $24 \%$ no período.

Em Araguaína - segunda colocada no ranking de valores repassados no período - foram 480 milhões de reais repassados em 10 anos. Em seguida, encontrase a microrregião de Porto Nacional (417 milhões de reais). Em 2017, cerca de 22 mil famílias recebiam, em média, $\mathrm{R} \$ 161,00$ por mês referentes ao benefício. Em Porto Nacional eram aproximadamente 15 mil famílias, com benefício médio de $\mathrm{R} \$ 166,00$ mensais.

$\mathrm{O}$ valor total dos repasses cresceu em todas as microrregiões no período analisado. O Gráfico 9 apresenta o percentual de variação entre 2007-2017 agregado por microrregião. Destacam-se Jalapão - em 115 que o valor total dos repasses mais que dobrou (104\%) -, Porto Nacional (94\%) e Dianópolis (80\%).

Apesar dos ganhos líquidos, houve uma inflexão em 2014: a partir desse período, o valor dos repasses (total, médio e per capita) entra em declínio. Entre 2014-2017, as microrregiões apresentaram entre 15\% (Dianópolis) e 30\% (Araguaína) de queda acumulada no valor total dos repasses. Para o valor médio, o percentual de queda esteve entre 7\% (Gurupi) e $15 \%$ (Porto Nacional).

Ao relativizarmos o valor total dos repasses pela população total da região (Gráfico 11), Jalapão surge como a microrregião de maior valor repassado per capita durante todo o período. Além dela, Bico do Papagaio, Dianópolis e Miracema estão, respectivamente, acima da média estadual. As regiões com menor valor repassado per capita foram Porto Nacional e Gurupi. 
Jalapão (74\%), Dianópolis (69\%) e Miracema do Tocantins (60\%), respectivamente, foram as regiões que apresentaram maior crescimento no valor per capita dos repasses no período, conforme apresentado no Gráfico 12. Em 2017, valor médio dos repasses no Jalapão - microrregião com o valor médio de repasse do Tocantins durante todo o período analisado - foi $41 \%$ maior que o valor médio dos repasses em Gurupi, região com o menor valor médio para este ano. Além do Jalapão, Bico do Papagaio e Dianópolis estiveram acima da média estadual entre 2007-2017. A evolução dos valores médios dos repasses pode ser vista no Gráfico 13.

$\mathrm{Na}$ microrregião de Jalapão, as famílias beneficiadas receberam, em média, $\mathrm{R} \$ 1.568,00$ dos repasses do PBF em 2007.

Em 2017, esse valor foi $73 \%$ maior: $\mathrm{R} \$$ 2.718,00 por família. Dessa forma, essa microrregião foi a que apresentou maior crescimento do valor média dos repasses no período analisado. Os percentuais de evolução podem ser vistos no Gráfico 14

Ao analisarmos o número absoluto de famílias beneficiadas pelo Programa Bolsa Família (Gráfico 15), Bico do Papagaio e Araguaína aparecem como os primeiros colocados. Nas últimas posições estão Rio Formoso e Jalapão. Contudo, ao ponderarmos a quantidade de famílias beneficiadas pela população total da região (Gráfico 16), Jalapão emerge como uma das regiões com maior proporção de beneficiários. Em 2017, mais de $11 \%$ da população da região foi diretamente beneficiada pelo Programa Bolsa Família. Além do Jalapão, as microrregiões do Bico do Papagaio, Dianópolis e Miracema do Tocantins estão bem acima da proporção de beneficiários do Tocantins (Gráfico 17). A região de Porto Nacional é a que apresenta o menor grau de beneficiários - entre 5\% e $6 \%$ durante todo o período.

Gráfico 9. Valor total dos repasses por ano - Em mil reais.

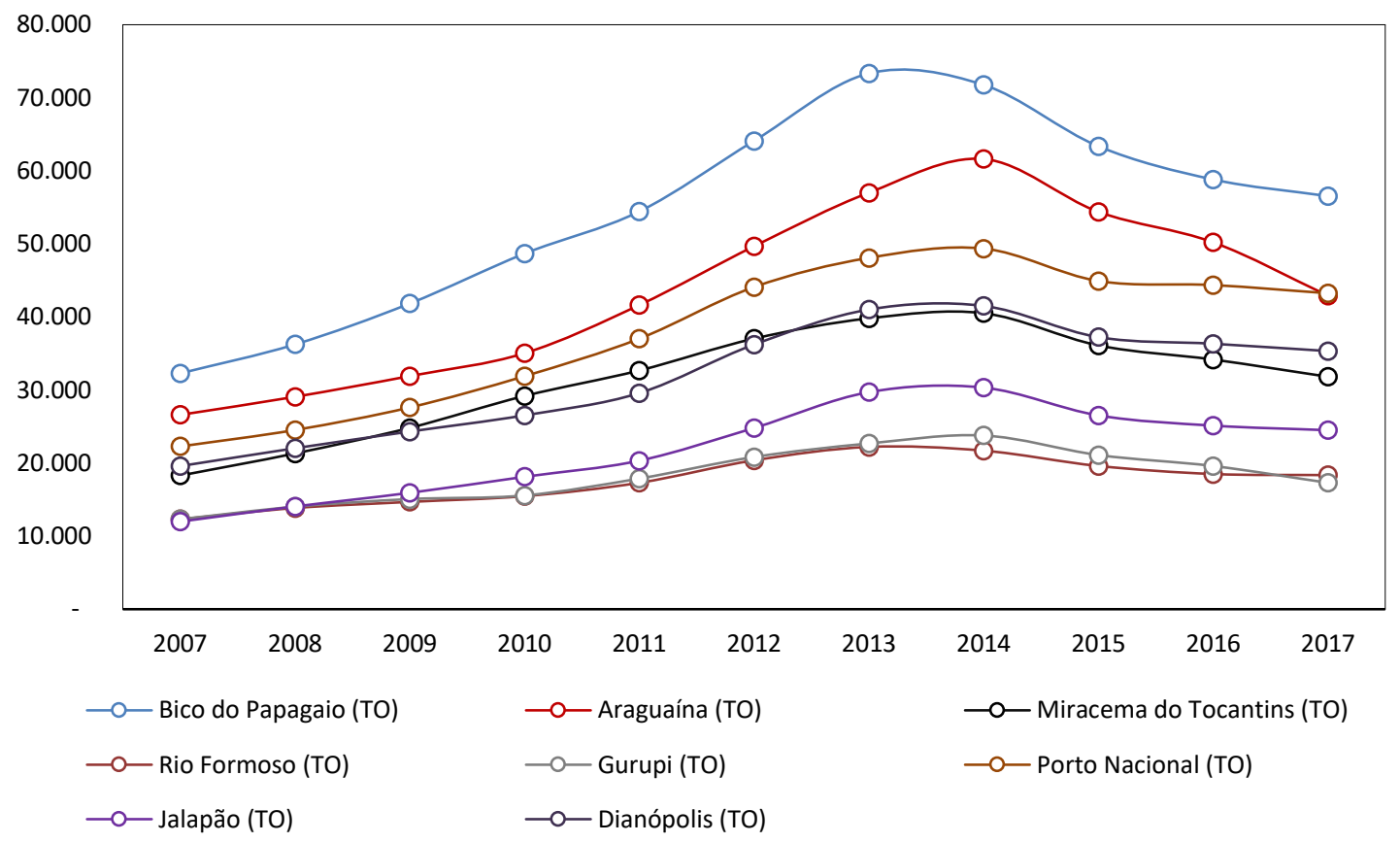

Fonte: Elaboração própria, a partir dos dados do Ministério da Cidadania (2007 a 2017) e IBGE (2019). 
]Gráfico 10. Variação entre 2007-2017 do Valor total dos repasses - Em porcentagem.

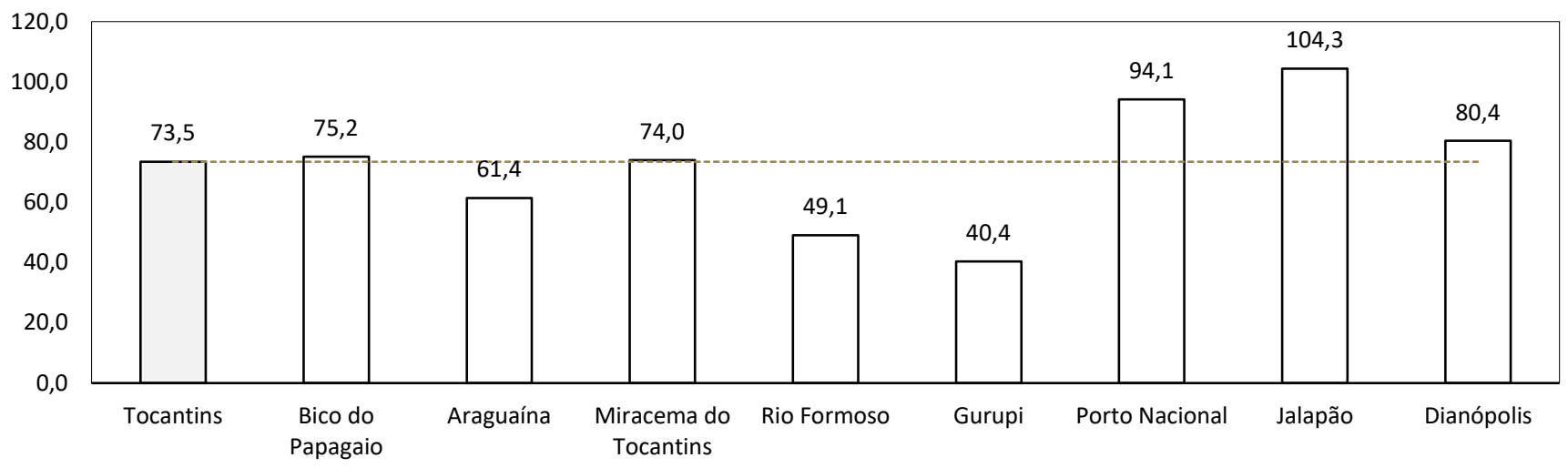

Fonte: Elaboração própria, a partir dos dados do Ministério da Cidadania (2007 a 2017) e IBGE (2019).

Gráfico 11. Valor per capita dos repasses por ano - Em reais.

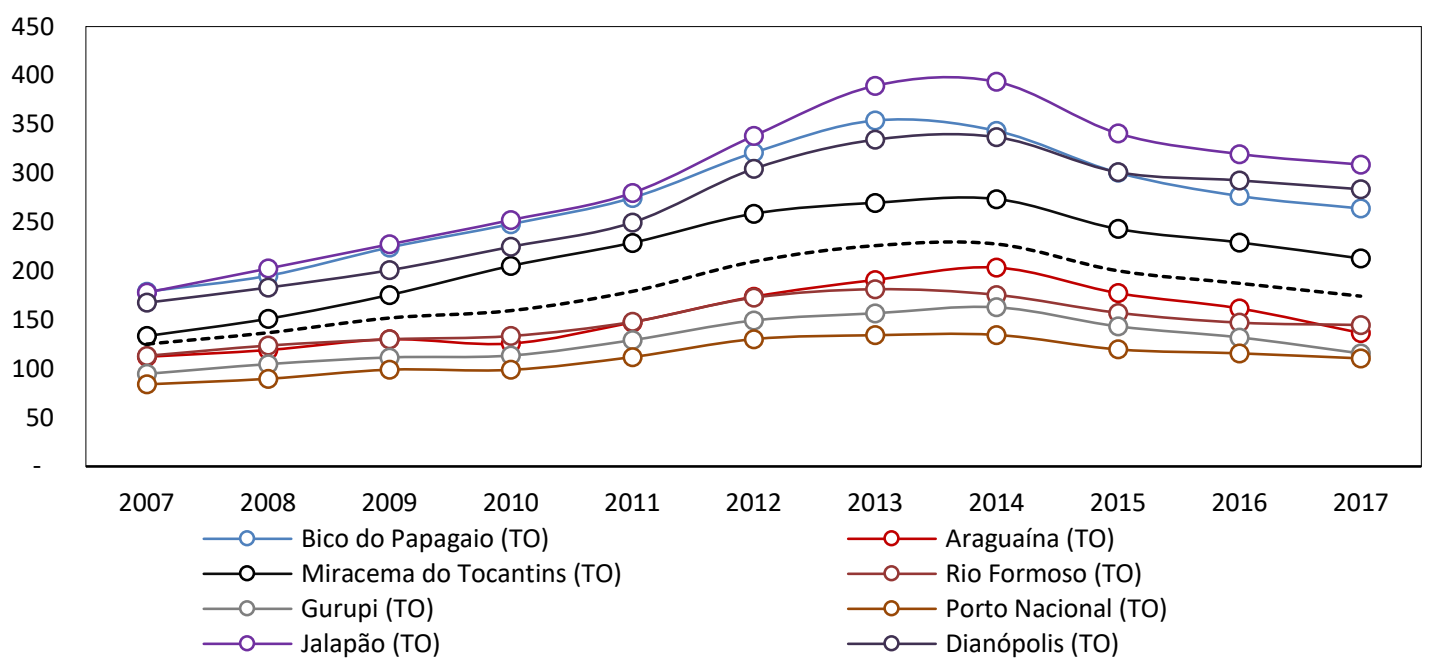

Fonte: Elaboração própria, a partir dos dados do Ministério da Cidadania (2007 a 2017) e IBGE (2019).

Gráfico 12. Variação entre 2007-2017 do Valor per capita dos repasses - Em porcentagem.

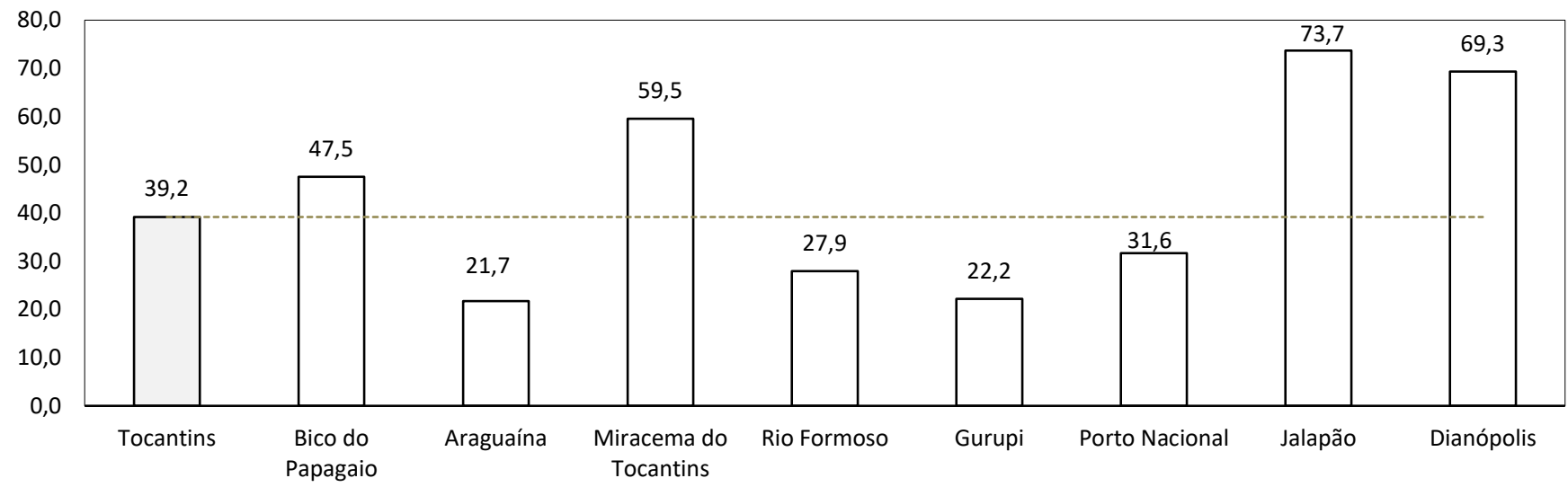

Fonte: Elaboração própria, a partir dos dados do Ministério da Cidadania (2007 a 2017) e IBGE (2019). 
Gráfico 13. Valor médio dos repasses por ano - Em reais.

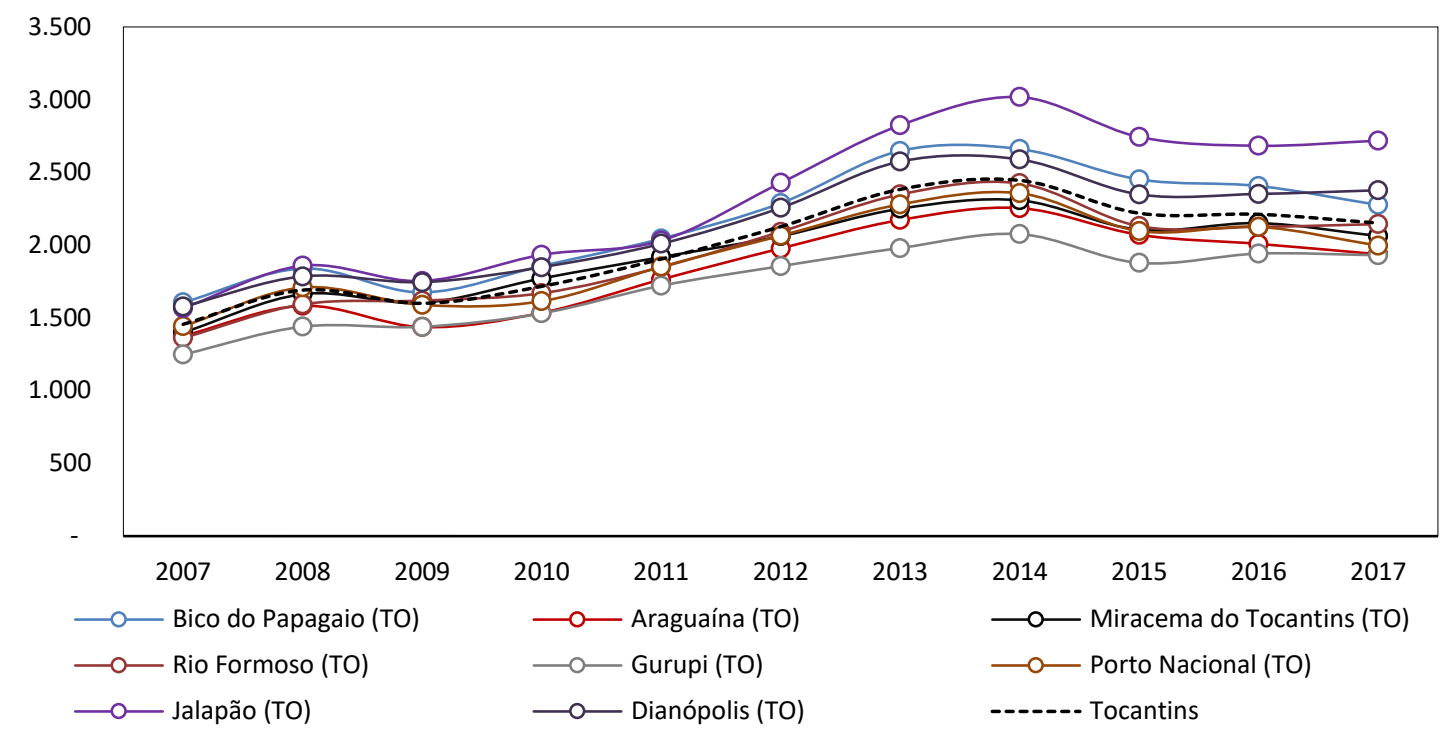

Fonte: Elaboração própria, a partir dos dados do Ministério da Cidadania (2007 a 2017) e IBGE

Gráfico 14. Variação entre 2007-2017 do Valor médio dos repasses - Em porcentagem.

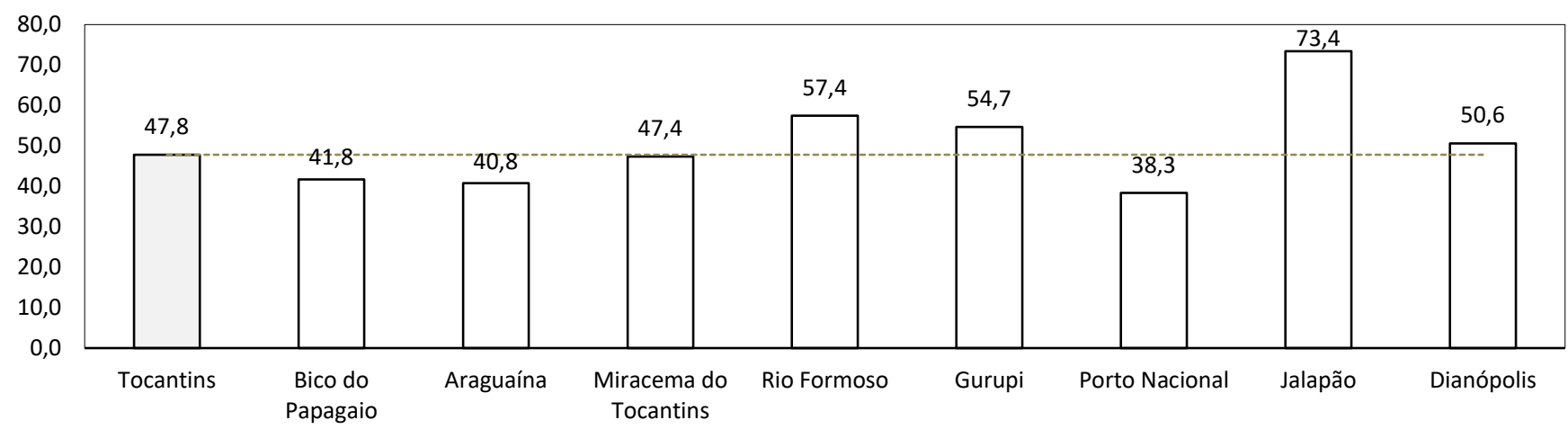

Fonte: Elaboração própria, a partir dos dados do Ministério da Cidadania (2007 a 2017) e IBGE (2019).

Gráfico 15. Quantidade de famílias beneficiadas.

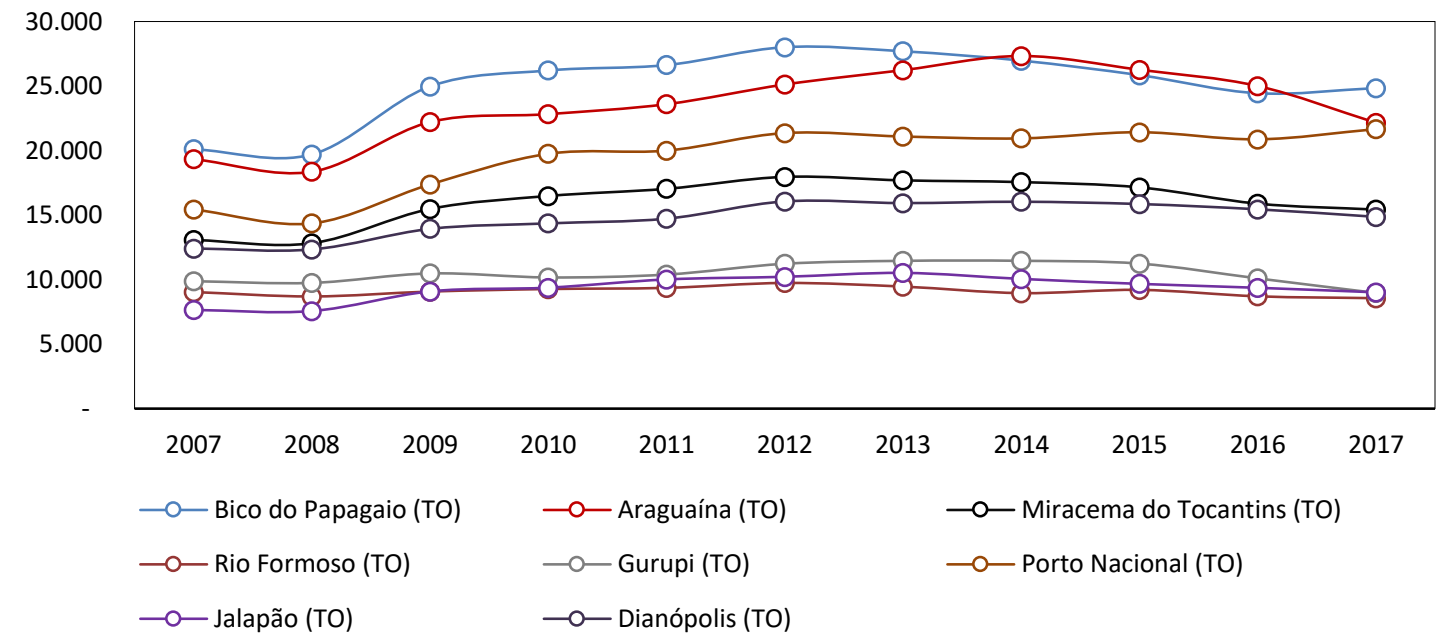

Fonte: Elaboração própria, a partir dos dados do Ministério da Cidadania (2007 a 2017) e IBGE (2019). 
Gráfico 16. Proporção de Beneficiários na População - Em porcentagem.

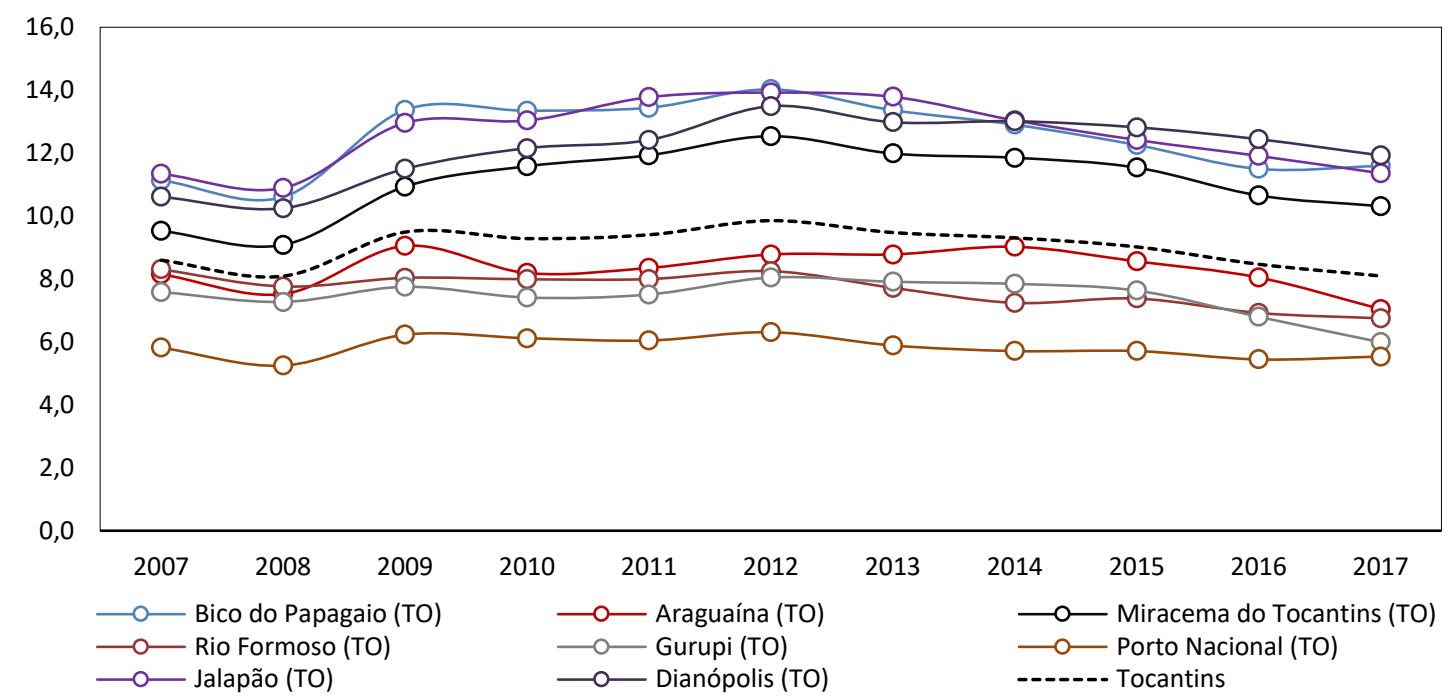

Fonte: Elaboração própria, a partir dos dados do Ministério da Cidadania (2007 a 2017) e IBGE (2019).

A quantidade de famílias beneficiadas diminuiu entre 2007-2017 em duas microrregiões: Gurupi (9\%) e Rio Formoso (5\%). Apesar das demais regiões terem apresentados ganhos líquidos na comparação entre 2007 e 2017, todas as regiões - com exceção de Porto Nacional - apresentaram valores acumulados negativos entre 2014 e 2017. Destacam-se Gurupi e Araguaína, com queda acumulada de $22 \%$ e 19\%, respectivamente, nos últimos três anos da série histórica.
Apesar da variação no número de famílias beneficiadas ter sido positiva, a variação da proporção de beneficiários (Gráfico 18) no Tocantins caiu entre 2007-2017. Gurupi foi a microrregião que apresentou a 119 maior diminuição: Em 2007, 7,6\% da população da região foi diretamente beneficiada pelo PBF, enquanto em 2017 foram 6,0\%. Dianópolis, por sua vez, apresentou o maior crescimento na proporção de beneficiários no período: de 10,6\% para $11,9 \%$ da população.

Gráfico 17. Variação entre 2007-2017 da Quantidade de Famílias Beneficiadas - Em porcentagem.

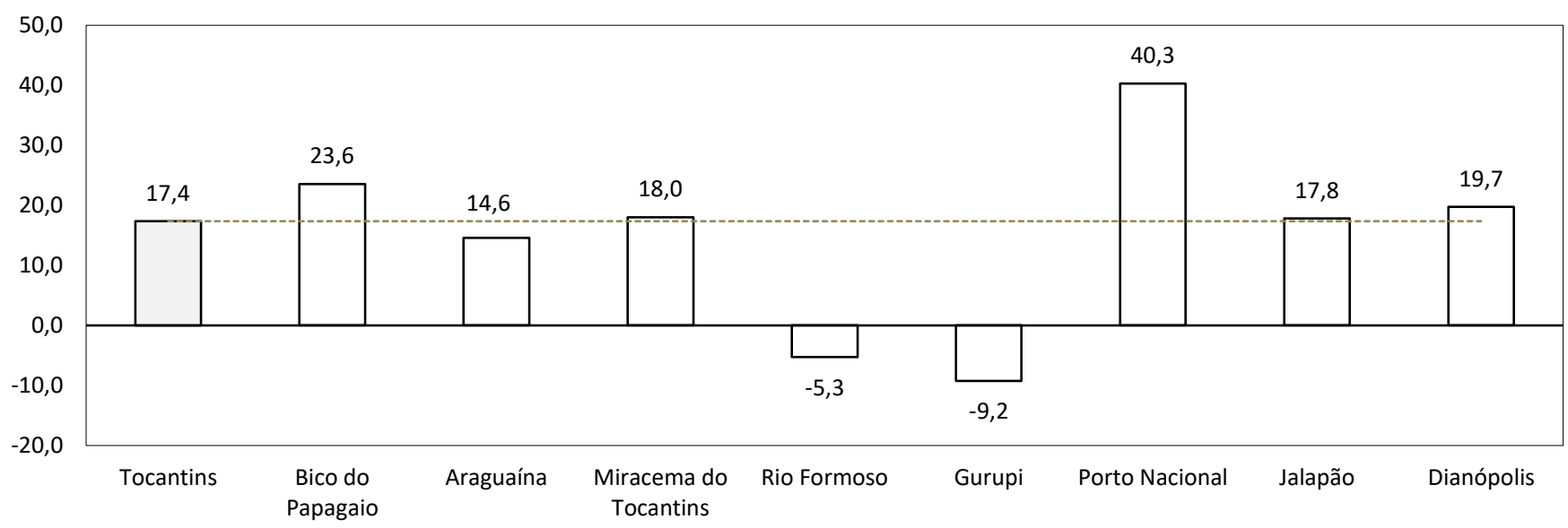

Fonte: Elaboração própria, a partir dos dados do Ministério da Cidadania (2007 a 2017) e IBGE (2019). 
Gráfico 18. Variação entre 2007-2017 da Proporção da Beneficiários na População - Em porcentagem.

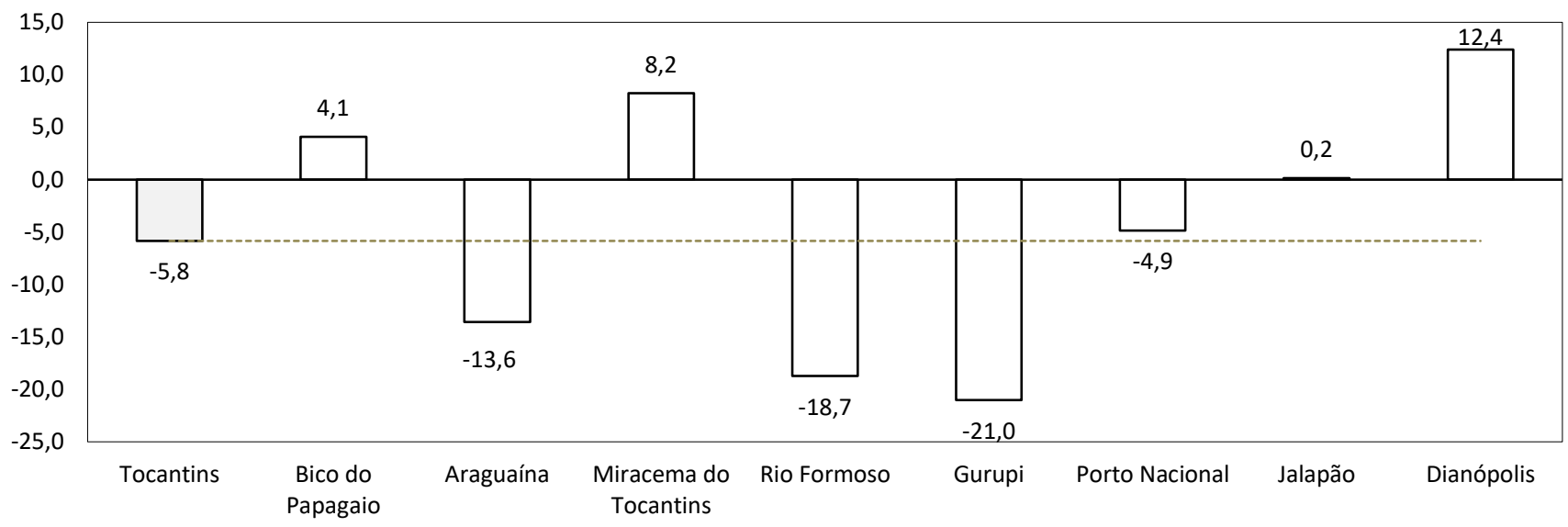

Fonte: Elaboração própria, a partir dos dados do Ministério da Cidadania (2007 a 2017) e IBGE (2019).

Em linhas gerais, tanto os valores repassados quanto a quantidade de beneficiários do Programa Bolsa Família cresceram em todas as microrregiões do Tocantins entre 2007-2017. Contudo, os dados sugerem haver duas fases do programa no estado: a de expansão - entre 2007 e 2013, e a de contração a partir de 2014.

As microrregiões de Jalapão, Bico do Papagaio e Dianópolis são as que possuem maior valor de repasses por habitante, bem como maior proporção de beneficiários na população (Gráfico 19 e 20). Este resultado vai ao encontro de outros indicadores socioeconômicos, que indicam que essas microrregiões são as regiões mais vulneráveis no Tocantins, do ponto de vista social, econômico e humano. A microrregião do Bico do Papagaio, conforme Oliveira e Strassburg (2014), aponta que se trata de uma região de extrema pobreza, com grandes desigualdades socioeconômicas, que foi palco de enormes conflitos agrários nas décadas de 1970 e 1980. O estudo de Milagres (2020) sobre os dilemas do desenvolvimento regional no Jalapão postula que a questão do acesso é uma das principais vulnerabilidades que afeta e desencadeia em inúmeros problemas na dinâmica socioeconômica local. Segundo Oliveira (2012), a região sudoeste, onde está inserida a microrregião de Dianópolis, possui baixa interação econômica com o seu entorno, uma vez que possui entraves que levam a baixa produção agropecuária na região.

Dessa forma, as regiões que possuem maior presença do Programa Bolsa Família - seja por volume de repasses ou volume de beneficiários por habitante são as regiões mais vulneráveis socioeconomicamente, marcada por fortes desigualdades e baixa dinâmica econômica e interação com o seu entorno.

Em contrapartida, as microrregiões de Porto Nacional e Gurupi (Gráficos 19 e 20) são as que possuem menor presença do Bolsa Família no Tocantins - seja por volume de repasses ou volume de beneficiários por habitante. Porto Nacional é a microrregião com maior dinâmica econômica do estado, uma vez que conjuga espaço econômico agropecuário e é polo dos setores secundários e terciários no Tocantins, além de possuir forte interação econômica com seu entorno (Oliveira, 2012). A microrregião de Gurupi, por sua vez, possui forte presença da agropecuária, e alta correlação produtiva com toda a região sudoeste do estado. Nesse 
sentido, as regiões que possuem menor presença do Programa Bolsa Família no Tocantins são as regiões com maior dinâmica econômica e forte interação com o seu entorno.

Gráfico 19. Valor per capita dos repasses e proporção de beneficiários nas Microrregiões do Tocantins - 2007.

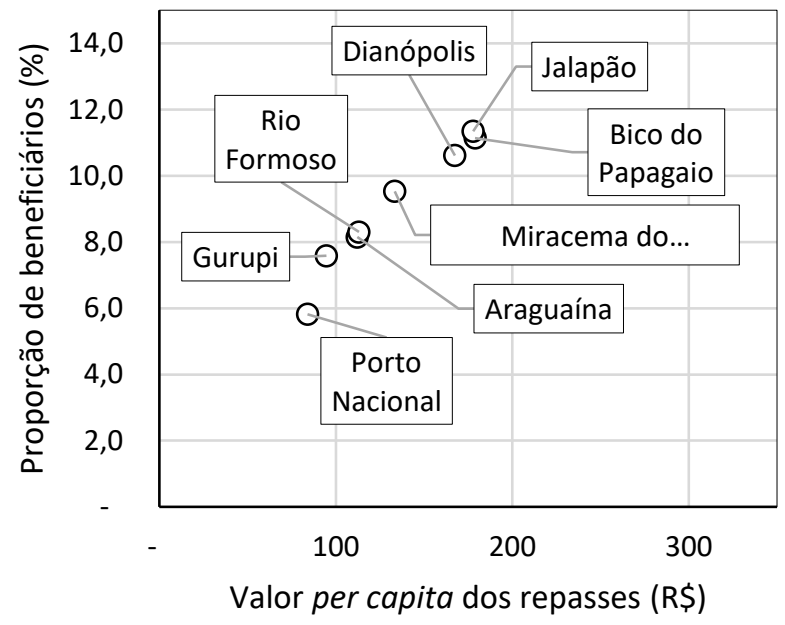

Fonte: Elaboração própria, a partir dos dados do Ministério da Cidadania (2007 a 2017) e IBGE (2019).

Gráfico 20. Valor per capita dos repasses e proporção de beneficiários nas Microrregiões do Tocantins - 2017.

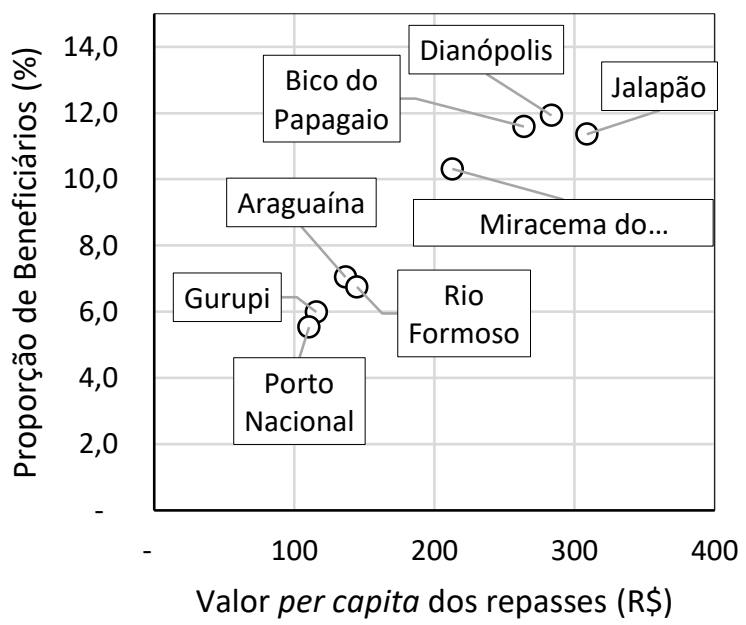

Fonte: Elaboração própria, a partir dos dados do Ministério da Cidadania (2007 a 2017) e IBGE (2019).

\section{CONCLUSÃO}

Neste artigo, buscou-se apresentar uma análise exploratória para os dados do Programa Bolsa Família no Tocantins entre 2007 e 2017, desagregados a nível de microrregiões. Além das variáveis oficiais do Ministério da Cidadania - valor total repassado, valor médio dos repasses e quantidade de famílias beneficiadas, foram calculados também o valor per capita dos repasses e a proporção de beneficiários na população.

A análise exploratória dos dados permitiu concluir que existiram duas fases do PBF no Tocantins entre 2007-2017: a de expansão - entre 2007 e 2013, e a de contração a partir de 2014. Essa tendência foi observada tanto nas variáveis de valor dos repasses como nas variáveis de volume de beneficiários.

As microrregiões do Jalapão, Bico do Papagaio e Dianópolis destacam-se como as regiões que possuem maior volume de repasses e beneficiários 121 por habitante. Essa conclusão corrobora com a situação de vulnerabilidade socioeconômica que apontam outros indicadores na região. Além disso, essas regiões foram selecionadas por programas de desenvolvimento territorial, tais como Programa de Territórios Rurais e da cidadania e Programa de Desenvolvimento Regional e Integrado, os quais selecionaram territórios considerados vulneráveis.

Por outro lado, Porto Nacional e Gurupi se sobressaem como as microrregiões com o menor volume de repasses e beneficiários por habitante, indo ao encontro dos demais indicadores socioeconômicos dessas regiões. Porto Nacional possui a maior dinâmica econômica do estado, pois congrega produção agropecuária com polarização do setor secundário e terciário do Tocantins. Gurupi, por sua vez, possui forte presença da agropecuária e alta correlação produtiva com toda a região sudoeste do estado. 
O presente estudo, contudo, não tem em seu escopo realizar afirmações sobre o fato de uma microrregião ter maior (menor) presença do Programa Bolsa Família seja compreendido como uma situação boa (ruim). Se por um lado, um baixo volume de beneficiários do programa pode indicar uma menor incidência de pessoas vivendo em situação de pobreza e extrema pobreza na região, por outro lado, pode indicar dificuldades da população - que de fato cumpre os requisitos de público-alvo - em acessar o PBF.

Nesta acepção, estudos recentes constataram um elevado percentual de exclusão do programa. De um modo geral, as análises evidenciam a existência de um contingente de famílias classificadas como pobres que ainda não conseguem acessar os benefícios do PBF (Mattei, 2015). Dessa forma, é possível que a focalização - ou a operacionalização - do programa precise ser ajustada.

Portanto, fazem-se necessários estudos que busquem compreender a dinâmica espacial e avaliar o impacto de políticas públicas e programas sociais, em especial a nível regional. Além disso, os resultados desta pesquisa demonstram a necessidade de políticas públicas - baseadas em evidência - que visem promoção do desenvolvimento regional mais equitativo entre as regiões do Tocantins.

Todos os autores declararam não haver qualquer potencial conflito de interesses referente a este artigo.

\section{REFERÊNCIAS}

AYDALOT, P. Economic régionale et urbaine. Paris: Econômica, 1985.

\section{ATLAS DO DESENVOLVIMENTO HUMANO NO} BRASIL - Consulta de Indicadores. Disponível em: <http://atlasbrasil.org.br/2013/pt/consulta/>. Acesso em: 10/04/2020
FERREIRA DE SOUZA, P. H. G. et al. Os efeitos do Programa Bolsa Família sobre a pobreza e a desigualdade: um balanço dos primeiros quinze anos. IPEA, n. 1415-4765, p. 46, 2019.

INSTITUTO BRASILEIRO DE GEOGRAFIA E ESTATÍSTICA - Censo Demográfico de 2010. Disponível em: <http://censo2010.ibge.gov.br/ >. Acesso em: 10/4/2020.

INSTITUTO BRASILEIRO DE GEOGRAFIA E ESTATÍSTICA - Produto Interno Brutos dos Municípios. Disponível em: https://sidra.ibge.gov.br/pesquisa/pib- munic/tabelas Acesso em: 13/04/2020.

INSTITUTO BRASILEIRO DE GEOGRAFIA E ESTATÍSTICA - IBGE. Censo Populacional, 2000 e 2010. Disponível em: http://www.ibge.gov.br . Acesso em: 11/04/2020.

INSTITUTO BRASILEIRO DE GEOGRAFIA E ESTATÍSTICA - IBGE. Divisão Regional do Brasil em Regiões Geográficas Imediatas e Regiões Geográficas Intermediárias 2017. Rio de Janeiro: [s.n.].

LUCAS, R. E. (1988). "On the Mechanics of Economic Development". Journal of Monetary Economics, vol. 22, n. 1, pp. 3-42. July, 1988.

MYRDAL, G. Teoria econômica e regiões subdesenvolvidas. 2. ed. Rio de Janeiro: Saga, 1957.

MATTEI, L. Politicas sociais de combate a probreza no Brasil. Revista da Sociedade Brasileira de Economia PolÍtica, v. 33, p. 147-176, 2012.

MILAGRES, Cleiton Silva F. O Sistema Socioecológico do Jalapão e os dilemas para o desenvolvimento regional. Tese (Doutorado em Desenvolvimento Regional) - Universidade Federal 
do Tocantins, Palmas, TO, 2020. BERALDO, Keile. Dimensões do desenvolvimento rural: uma análise dos proinfs no território bico do papagaio do Tocantins.

MYRDAL, G. Teoria econômica e regiões subdesenvolvidas. 2. ed. Rio de Janeiro: Saga, 1957.

OLIVEIRA, J. M. M. As mudanças no perfil do eleitorado brasileiro. In. PEREIRA, Z. (Org.) Ensaios contemporâneos sobre o Estado do Tocantins. Goiânia: Ed. Da PUC Goiás, 2009.

OLIVEIRA, N. M.; PIFFER, M. Determinantes do Perfil Locacional das atividades produtivas no Estado do Tocantins. Boletim de Geografia (UEM), v. 36, p. 92-111, 2018.

OLIVEIRA, Nilton Marques; PIFFER, Moacir; STRASSBURG, Udo. O Indicador de Desenvolvimento Regional no Território do Tocantins. Interações Campo Grande, v. 20, n. 1, p. 3-20, Jan. 2019. Disponível em: $<$ http://www.scielo.br/scielo.php?script=sci_artt ext\&pid=S1518-

70122019000100003\&lng=en\&nrm=iso >.

Acesso em: 05/05/2020.

OLIVEIRA, Thiago José Arruda de. Interações produtivas no estado do Tocantins: uma análise espacial. 2012. 90f. Dissertação (Mestrado em Desenvolvimento Regional) Universidade Federal do Tocantins, Programa de Pós-Graduação em Desenvolvimento Regional, Palmas, 2012.

OLIVEIRA, T.; RODRIGUES, W. O Desempenho das Regiões Econômicas do
Tocantins em Tempos de Crise (2010-2015): Uma Análise Espacial. Desenvolvimento Regional em Debate, v. 9, n. 2237-9029, p. 521$541,2019$.

PERROUX, F. Note sur la notion de póle de croissance. Tradução com permissão da Revista Brasileira de Estudos Políticos. Economie appliquée, 1967.

SEN, Amartya. Desenvolvimento como liberdade, $S$. Paulo: Cia. das Letras, 2000.

SOARES, S. et al. Os impactos do benefício do programa Bolsa Família sobre a desigualdade e a pobreza. Brasília: IPEA, 2010. v. Vol. 2

SOUZA, C. V. A invenção do Tocantins. Espaço e tempo na construção da comunidade imaginada em um 123 contexto regional. Ciências Humanas em Revista Historia, 6(2), p. 49-63, 1995.

RAJ, D. Development Economics. Princeton: Princeton University Press, 1998.

SCHUMPETER, J. A. [1911]. A Teoria do Desenvolvimento Econômico. São Paulo: Abril Cultural, 1983.

WANDERLEY, M. N. B.. 2009. O mundo rural brasileiro: acesso a bens e serviços e integração campo-cidade. Estudos Sociedade e Agricultura (UFRJ), v. 17, p. 60-85. 